\title{
Effectiveness of Systems Application on Financial Performance of Supermarkets in Kenya
}

\section{Collins Ochieng Obura}

School of Business and Economics, Turkana University College, Lodwar, Kenya

\author{
Email address:
}

cobura@tuc.ac.ke

\section{To cite this article:}

Collins Ochieng Obura. Effectiveness of Systems Application on Financial Performance of Supermarkets in Kenya. American Journal of Operations Management and Information Systems. Vol. 6, No. 3, 2021, pp. 52-57. doi: 10.11648/j.ajomis.20210603.13

Received: August 10, 2021; Accepted: August 23, 2021; Published: August 30, 2021

\begin{abstract}
The scramble for space in the retail industry has forced most supermarkets into adopting alternative strategies that will enable them attract customers, reduce operational costs and gain competitive edge in the market. This study discusses the application of systems with integrated database that are able to create enabling environment for efficient retail management. Bar coding and Continuous Replenishment System are the key variables used to get more insight into the study. The study adopted a cross-sectional survey design. A stratified sampling method was used to select a sample from the total population. From each stratum, the study used a random sampling to select $30 \%$ of the respondents which made a sample of 42 respondents. Data was collected using questionnaires and analysis done using statistical package for social science to communicate research findings. The ANOVA findings as explained by the P-Value of 0.000 which is less than 0.05 (significance level of 5\%) confirms the existence of correlation between the independent and dependent variables. From the study findings, the study concludes that the introduction of barcode and continuous replenishment systems at an early stage of supermarket operation will enable the business to create greater responsiveness to its customers and suppliers, understand its cash flow needs, protect its financial data and confidential executive decisions and reduce its operation expenses leading to higher profitability and financial performance.
\end{abstract}

Keywords: Systems Application, Barcoding, Continuous Replenishment System, Financial Performance and Supermarkets

\section{Introduction}

Arguments on the use of systems in management practices since the introduction of Internet have always been held with those supporting system integration arguing that it is efficient, has greater Accuracy and enables labor costs reduction through time saving. The digital revolution has also enabled businesses to have seamless flow of information and maintain customer relationship [1] This signals that businesses are moving away from the cumbersome paper transactions to the modern concept of Electronic Commerce. According to [2] Best practices in modern technological development increasingly call for an agile approach to developing the technology and software solutions. Systems that are used in supply chain and can as well be adopted in retail chain management includes; Enterprise resource planning, which provides a great deal of capability in the management process as it allows managers from all functions to have a consolidated view of activities throughout the operating enterprise. The second is the Distribution Requirement Planning used in handling replenishment in multi echelon environment. The word multi-Echelon as described by [3], means that instead of independent control of the same item at different distribution point using the Economic Order Quantity formulae, the dependent demand at higher echelon (such as central warehouse) is derived from the requirements of lower echelons (such as regional warehouses). The third is the Radio Frequency Identification (RFID) technology. This makes organizations more effective by enabling real-time visibility of information regarding items in and out of the supermarkets. According to [4], RFID technology has matured to the point where such systems can be implemented in a scale-able and cost-effective manner, hence ensuring significant return on an organization's investment. Where retail chains wants effective coordination with the suppliers, Vendor managed Inventory is recommended. This kind of arrangement is where retailer is in possession of stocks but the goods are still owned by the 
supplier. In this case, Payment of the inventory is made once it is sold [5]. Barcode scanner which is the backbone operating system for many supermarkets plays a very important role in data capture and decision making. According to [6], barcodes provide a rapid, accurate and efficient means to collect, process, transmit, record and manage data in a variety of industries.

\subsection{Background of Supermarkets in Kenya}

Pioneered by the likes of Walmart, the growth of supermarket in Kenya picked up after the country attained independence in 1963. In 1975, Uchumi supermarket became the first retail chain to operate in the country under the companies act (cap 486 of the 2 laws of Kenya) where it became a leader in offering lower prices for its products as a competitive edge and at the same time maintaining high standards in quality of goods and services they offered to their customers. Other retail chains which were operational included Nakumatt Holdings Limited which was mostly found in superb locations targeting high end customers. Tuskys Limited which began trading as Tusker supermarket became operational in 2000. Unlike Nakumatt, Tuskys was mainly found in strategic crowded places targeting middle and lower cadre of customers. This made it to pick up and grow into a formidable competitor in the retail industry. Other retail chains included Naivas, Ukwala and Tumaini supermarkets respectively. These retail chains adopted the strategies used by Tuskys Limited with regard to their location and also became a force in the market. The creation of the 2010 constitution opened the economy to regional blocks enabling supermarkets to spread all over the country. In western part of the country which includes Nyanza and the former western province, many supermarkets (apart from Uchumi) opened several branches where they offered variety of products to their customers ranging from garments, furniture to food chains.

\subsection{Statement of the Problem}

The question of how to manage stock levels and easily identify stocks through various stages from original location to load assembly is a major puzzle for most retail chains. Globally, the emergence of the internet and the introduction of E-commerce has led to retail industries experiencing an unprecedented change in the current competitive market. In Kenya for example, the rate at which supermarkets diminish from the industry is alarming. Uchumi Supermarket which was one the largest retail chain in Kenya went under receivership in 2006 due to financial and operational difficulties. In 2018, Nakumatt Holding Limited which was the $2^{\text {nd }}$ largest retail chain in the country went down due to financial mismanagement. [7] documents that as a result of rapid expansion, Nakumatt Supermarket underwent through cash flow problems that saw a lot of liquid resources go into the purchase of the stocks within a shorter period of time. A report by the Association of suppliers [8] also showed that the retail chains (Nakumatt holding Limited and Tuskys
Limited) had a $41 \%$ and a $9 \%$ share respectively of outstanding debt of 60 days and above that it owed to suppliers. In a rejoinder, a study by the State Department for Trade [9] on 'Kenya retail sector prompt payment' listed some of the unfair trade practices by the retailers including; retailers exploiting the advance information on products they have and using such information to develop their own private labels hence giving suppliers unfair deal and denying them business in return.

\section{Literature Review}

\subsection{Barcode System}

In modern business operations, managers make decisions based on the available information at their disposal. Implementation of the right technology gives management and organization ease of operation and the opportunity to effectively be competitive in the market. When adopted at an early stage by supermarkets, barcode system provides operational efficiency, improves speed, accuracy and tracking and sorting of stocks. It easily captures information that would be difficult to collect in other ways. This help managers to fully make informed decisions.

Barcode scanner collects data for input into a computer. This function is also performed by the Electronic Point of Sale (EPOS). However for customer relation, Electronic point of sale is used to give real time information. EPOS is most visible in the check-out counter of supermarket where it records stores sales and the products which are in stock, and provides customers with their payment information. According to [10] the application of electronic point of sale allows substantial cost savings and gives "real time" information on sale of goods patterns of stores traffic, and popularity and profitability of every line carried. The scanner is important in Provision of information to customers relating to products and prices and is used as an electronic article surveillance in the detection and prevention of shop lifting. This makes it an important system with regard to retail management.

Just like the barcode scanners, Radio frequency identification (RFID) tags also carry information about products. One advantage of RFID over barcode scanner is that RFID readers can read RFID tags much faster as compared to barcodes which takes much time since it require a direct line of sight for it to capture details of the product [11]. However Since RFID systems uses electromagnetic spectrum like Wi-Fi networks, they are relatively easy to jam using energy at the right frequency thus causing inconvenience for consumers in supermarkets. This challenge on RFID tags makes barcode scanners the effective system to use for data capture in supermarkets.

\subsection{Continuous Replenishment System}

Even with the use of demand data to perform sale forecast updates, Inventory reductions and discrepancies of upto $20 \%$ are still being experienced in retail operations. This 
imbalance in buying practices becomes a contributing factor to unnecessary fluctuations in the order data [12]. To make necessary materials available when needed in supermarket and in other retail chains, Continuous Replenishment System which is a tool in supply chain management is used. The replenishment system is often triggered when there are only few stock left in the store [1]. According to [13] the introduction of continuous replenishment system to supermarket operations is basically to develop free flowing fulfillment of orders and delivery systems, so that bottlenecks can be substantially reduced. So as to minimize the sum of overall costs associated with the production, storage and inventory shortage per unit of time or for a specific amount of time, management should develop strategies to enable them know how large an inventory replenishment is and also the time the replenishment should be made [14]. The strength of a firm's information system therefore becomes crucial with respect to efficiency in providing real time information on the required items.

\section{Research Methodology}

Conducted in 2020, a cross-sectional survey was used. According to [15], a cross- sectional designs involves the analysis of data collected from a population, or a representative subset at one specific point in time. The study population comprised of Top management level and lower level management staff of top three supermarkets in the western region namely Tuskys Limited, Khetias and Naivas Supermarket respectively as shown in the table 1 below.

Table 1. Target Population.

\begin{tabular}{|c|c|c|c|c|c|}
\hline & Segments & Tuskys Limited & Khetias Supermarket & Naivas Supermarket & Total Target \\
\hline Target & Top Level Management & 9 & 9 & 9 & 27 \\
\hline Population & Lower Level Management & 36 & 36 & 36 & 108 \\
\hline TOTAL & & 45 & 45 & 45 & 135 \\
\hline
\end{tabular}

Sample Size: A stratified sampling method was used to select a sample from the population. From each stratum, the study used a random sampling to select $30 \%$ of the respondents which made a sample of 30 respondents as shown in the table 2 below. Data was collected using questionnaires and analysis done using statistical package for social science to communicate research findings.

Table 2. Sample Frame.

\begin{tabular}{|c|c|c|c|c|c|c|}
\hline & Segments & Percentage (\%) & Tuskys Limited & Khetia Supermarket & Naivas Supermarket & Total Target \\
\hline Sample & Top Level Management & $30 \%$ & 3 & 3 & 3 & 9 \\
\hline Size & Lower Level Management & $30 \%$ & 11 & 11 & 11 & 33 \\
\hline TOTAL & & & 14 & 14 & 14 & 42 \\
\hline
\end{tabular}

The study used the following regression model:

$$
\mathrm{Y}=\beta 0+\beta 1 \mathrm{X} 1+\beta 2 \mathrm{X} 2+\varepsilon
$$

Whereby;

$\mathrm{Y}=$ Financial Performance of Supermarkets in Kenya

$\beta 0=$ Constant, explaining the level of performance

$\beta 1=$ Slope or change in $\mathrm{Y}$, given one unit change in $\mathrm{X} 1$

$\mathrm{X} 1=$ Barcoding

$\mathrm{X} 2$ = Continuous Replenishment System

$\varepsilon=$ represents the error term explaining the variability of the quality of effectiveness as a result of other factors not counted for.

\section{Descriptive Analysis}

\subsection{Response Rate}

[16] asserts that a response rate of above $50 \%$ is adequate for analysis while a response rate at $70 \%$ and above is excellent for analysis. The response from the sampled respondents for this study was 36 out of 42 making a response rate of $85.7 \%$ hence is excellent for analysis.

\subsection{Barcoding}

Table 3. Statements relating to Barcoding.

\begin{tabular}{|c|c|c|}
\hline Statement & Mean & Std deviation \\
\hline Barcoding system helps in stock level verification and identification of stock locations & 4.89 & 0.01 \\
\hline It creates greater responsiveness to customers and supplier & 4.19 & 0.02 \\
\hline The Barcode scanner provides greater accuracy and faster data entry of stocks & 4.64 & 0.04 \\
\hline
\end{tabular}

Table 4. Statement relating to Continuous Replenishment System.

\begin{tabular}{lll}
\hline Statement & Mean & Std deviation \\
\hline Continuous replenishment allows supermarkets to see demand patterns for its products & 0.05 & 3.94 \\
There is customer satisfaction due to timely stock replenishment & 4.75 \\
Better forecasting as a result of information sharing among trading partners & 0.04 & 4.33 \\
\hline
\end{tabular}


Regression analysis: Regression model was applied to determine the relative importance of each of the two indicators on financial performance of Supermarkets in Kenya. The regression model was as follows: $Y=\beta_{0}+\beta_{1} X_{1}+\beta_{2} X_{2}+\varepsilon$.

Using the values of the coefficients $(\beta)$ from the regression coefficient table 5 the established multiple linear regression equation takes the form of;

$$
\mathrm{Y}=2.867+0.463 \mathrm{X}_{1}+0.373 \mathrm{X}_{2}+\varepsilon
$$

Where;

Constant $=2.867$; when value of the independent variables are zero, Financial Performance of Supermarkets in Kenya would take the value 2.867 .

$\mathrm{X}_{1}=0.463$; One unit increase in bar coding results in 0.368 units increase in performance of supermarkets in Kenya.

$\mathrm{X}_{2}=0.373$; One unit increase in results in 0.373 units increase in performance of supermarkets in Kenya.

Table 5 Regression Coefficients

\begin{tabular}{|c|c|c|c|c|c|c|}
\hline \multirow{2}{*}{ Model } & & \multicolumn{2}{|c|}{ Unstandardized Coefficients } & \multirow{2}{*}{$\begin{array}{l}\text { Standardized Coefficients } \\
\text { Beta }\end{array}$} & \multirow{2}{*}{$\begin{array}{l}\mathbf{T} \\
\mathbf{B}\end{array}$} & \multirow{2}{*}{$\begin{array}{l}\text { Sig. } \\
\text { Std. Error }\end{array}$} \\
\hline & & B & Std. Error & & & \\
\hline \multirow{3}{*}{1} & (Constant) & 2.867 & 2.225 & & 1.431 & .005 \\
\hline & Barcoding & .368 & .028 & .346 & 2.253 & .004 \\
\hline & Continuous replenishment & .252 & .033 & .276 & 3.223 & .002 \\
\hline
\end{tabular}

Dependent Variable: Financial Performance of Supermarkets in Kenya.

The results as shown in the table 6 indicates that the coefficient of regression, $\mathrm{R}=0.864$ shows a good strength of the relationships between independent variables and the dependent variable. The coefficient of determination $\mathrm{R}^{2}=$ 0.746 shows the predictive power of the model and in this case $74.6 \%$ of variations in the performance in performance of supermarkets in Kenya. is explained by the changes in bar coding and continuous replenishment system independent variables. The adjusted coefficient of determination $\mathrm{R}^{2}$ shows the predictive power when adjusted for degrees of freedom and sample size. In this case, after the adjustments $70.3 \%$ of the variations in the performance of supermarkets in Kenya is explained by the independent variables.

Table 6. Model Summary.

\begin{tabular}{lllll}
\hline Model & R & R Square & Adjusted R Square & Std. Error of the Estimate \\
\hline 1 & $.864(\mathrm{a})$ & .746 & .703 & .08487 \\
\hline
\end{tabular}

Predictors: (Constant), Bar Coding, Continuous Replenishment System.

Dependent Variable: performance of supermarkets in Kenya.

ANOVA findings as explained by the P-Value of 0.000 which is less than 0.05 (significance level of $5 \%$ ) confirms the existence of correlation between the independent and dependent variables. The model shows the model fitness i.e. how well the variables fit the regression model. From the results, the F ratio of 28.443 and the significance of 0.000 shows that there was not much difference in means between dependent and independent variables. The sum of squares gives the model fit and hence the variables fit the regression model.

Table 7. ANOVA.

\begin{tabular}{lllll}
\hline Model & Sum of Squares & d.f. & Mean Square & F \\
\hline Regression & 59.643 & 2 & 15.223 & 28.443 \\
Residual & 24.431 & 34 & .287 & $.000(\mathrm{a})$ \\
Total & 73.074 & 36 & & \\
\hline
\end{tabular}

Predictors: (Constant), Bar Coding, Continuous replenishment.

\section{Discussion}

Survival of retail chain operations largely depend on their financial performance in the market. From Michael Porter's value chain analysis, information technology which is a support activity plays a key role in ensuring higher profit margin for any firm. This study as well recognizes the importance of technological impact in retail industry. From the study findings, the role played by barcode scanner in stock level verification and identification of stock locations is represented by a mean of 4.89 while in terms of greater responsiveness to customers and customers, the findings are represented by a mean of 4.19. Provision of accurate and faster of entry of data is represented by a mean of 4.64. According to [17] the importance of bar scanners and its greater application can be deduced from its capacity to carry a lot of data and can be used to support pre-sale, buy-and-sell, post-sale activities for e-commerce transactions.

When supermarkets use such systems such as continuous replenishment systems, they are able to develop an effective inventory control system to manage customer's demand and also properly manage costs associated with stock control such as; carrying costs, ordering and storage costs respectively. From the findings, customer satisfaction due to timely stock replenishment is represented by a mean of 4.75 
while better forecasting of demand was rated by a mean of 4.33. These findings corresponds with the findings of [13] which documents that Proper and timely determination of the optimal inventory control strategy allows freeing a significant amount of assets, frozen in the form of stocks, which ultimately increases the efficiency of resource use.

\section{Conclusion}

No matter the size of the retail, technology has both tangible and intangible benefits that will help it make money and produce the results that customers demand. From the benefits of creation of smart shelves which read and transmit data through the internet to the stores managers and suppliers notifying them when stocks are low to better demand forecasting, customer satisfaction level increases. When customers are satisfied, firms make more sales which increases their revenue volumes and subsequently raising their profit margin making them financially capable thus becoming a leader in the market. Therefore the introduction of barcode and continuous replenishment systems at an early stage of supermarket operation will enable the business to create greater responsiveness to its customers and suppliers, understand its cash flow needs, protect its financial data and confidential executive decisions and reduce its operation expenses leading to higher profitability and financial performance.

\section{Recommendation}

\subsection{ERP System}

Supermarkets are required to undertake continuous stock taking to check physically the stock items in order to ascertain that stock quantities shown on stock records and actual quantities are the same. According to [18], one advantage of continuous stock taking is that it enhances detection of discrepancies in time and acts as a deterrent to malpractices. However with the modern technological developments, carrying out such activities require systems that saves on cost and are designed around a number of modules each of which can stand alone or combine with others. Together with the barcode scanner, ERP system implementation for supermarkets increases efficiency, shorten the time lead for the stock-taking process and reduces inventory holdings hence leading to savings on working capital.

\subsection{Employee Training to Build Capacity}

The dynamics of growth in the retail industry including the increasing number of competitors, current trend of emerging technologies and the fragmentation of market segmentation require that supermarkets offer training and development to their employees. This will increase the service levels and customer satisfaction hence increasing the sales volume which will make the supermarket to have a higher market share.

\subsection{Code of Practice}

Codes of practice are norms and values that are expected of the general employees of an entity. Having code of conduct at a work place shall pre-empt legal actions in case of right violations and will dictate what is expected both the employees and suppliers when transacting business. A good code of practice which values the working relationship between partners is good for growth and financial performance of any operating entity.

\section{References}

[1] Rushton. A., Croucher. P., Baker. P. (2010), The Handbook of Logistics and Distribution Management. $4^{\text {th }}$ edition.

[2] Nikoloski, K. (2014). The Role of Information Technology in the business sector. International Journal of Science and Research. Volume 3 Issue 12. 306.

[3] Vollman. T. E., Berry. W. L. and Whybark D. C., (1997). Manufacturing Planning and Control Systems (Homewood: Irwin).

[4] Miles, Bell (2011) RFID Technology and Applications, London, Cambridge University Press.

[5] Kumar, P., \& Kumar, M. (2003). Vendor managed inventory in retail industry. White Paper, Tata Consultancy Services. Retrieved from http://www.tcs.com/ (accessed on 24 May 2006).

[6] Darlington, W. (2009). "Purchasing and Supply Material". $7^{\text {th }}$ Edition published in New Delhi.

[7] Shisia, A., Sand, W., \& Okibo, W. (2014). An in-depth analysis of the Altman's failure Prediction model on corporate financial distress in Uchumi supermarket in Kenya. European Journal of Business Management, 6 (23), 27-41.

[8] Kenya Association of Manufacturers, (2016). Annual Report 2016.

[9] State department for trade report: (2017). Study on Kenya retail sector prompt payment.

[10] Lwiki, T., Ojera, P., Mugendi, N., \& Wachira, V. (2013). The impact of Inventory Management Practices on Financial Performance of Sugar Manufacturing Firms in Kenya. International Journal of Business, humanities and Technology, 3 (5), 75-85.

[11] Bhatt, H. and Glover, B. (2006) RFID Essentials. O'Reilly Pub, New York.

[12] Lee, H. M., and Yao, J. S. (1998). Economic Production Quantity for Fuzzy Demand and Fuzzy Production Quantity. European Journal of Operational Research, 109: 203-211.

[13] Baily, P., Farmer, D., Crocker, B., David, J., Jones, J., (2018). Procurement principles and management. $10^{\text {th }}$ edition.

[14] Ziukov. S. (2015). A literature review on models of inventory management under uncertainty.

[15] Babbie, E. (2007). The practice of Social research. 11 ${ }^{\text {th }}$ Edition. Thompson Wadsworth, Belmont. 
[16] Cooper, D. R., \& Schindler, P. S. (2014). Business Research Methods. New York: McGraw-Hill/Irwin. (12th ed.).

[17] Kato, \& Tan. (2007). 2D barcodes for Mobile Phones. Proceedings of 2nd. International Conference on Mobile
Technology, Applications and. Systems. Retrieved April 25, 2017.

[18] Saleemi, N. A. (2017). "Storekeeping and stock control simplified" Solutions Publishing co. Nairobi Kenya. 